\title{
Causes Analysis of the Serious Road Traffic Accidents Cases
}

\author{
Xuewen Zhang ${ }^{1, a}$, Fei Huang ${ }^{2, b}$ and Cheng Zeng ${ }^{1, c}$ \\ ${ }^{1}$ Key Laboratory of Operation Safety Technology on Transport Vehicles, Research Institute of \\ Highway of Ministry of Transport, Beijing 100088, China \\ ${ }^{2}$ School of Transportation, Jilin University, Changchun 130022, China \\ axw.zhang@rioh.cn, bhuangfeiyz@foxmail.com, ${ }^{\mathrm{c}} \mathrm{c} . z e n g @$ rioh.cn
}

Keywords: Serious road traffic accidents, Genetic characteristics, Genetic model, Cases analysis, Preventive measures.

Abstract: Since road traffic accidents have become a serious public hazard for social development, it is necessary to study the causes of serious road traffic accidents that have significant social impacts. The genetic characteristics of the serious road traffic accident have been pointed based on the analysis of a serious road traffic accident, combined with the genetic model of the road traffic accidents for cause analysis of the accident cases. It makes some commendations on measures to prevent the serious road traffic accidents.

\section{Introduction}

Automobiles not only bring comfort and efficiency to human activities, but cause a large number of road traffic accidents, and has caused enormous material and moral damage to human society ${ }^{[1]}$. According to the official statistics released in 2013, there were 198,394 road traffic accidents involving casualties in China, resulting in the death of 58,539 people, making 213,724 people injured and direct property losses of 1.04 billion yuan. There were 834 road traffic accidents that a death occurred more than 3 , reducing by 187 cases. There were 209 road traffic accidents that a death occurred more than 5 , reducing by 37 cases. There were 16 serious road traffic accidents that a death occurred more than 10 , reducing by 9 cases $^{[2]}$.

In China the road traffic safety situation is fairly grim, and the serious road traffic accidents are frequent. Due to more deaths, huge property losses and bad social influence caused by the serious road traffic accidents.

Based on the researches on a typical serious road traffic accident case, we get a summary of genetic characteristics of road traffic accidents that more than 10 people died, and analysis the causes. In addition, recommendations that are related to preventing and reducing this type of accident are put forward.

\section{Genetic model of the serious road traffic accidents}

\section{Reason Model}

Reason Model is the conceptual model that was proposed by Reason J. in $1990^{[3]}$. Later, Reason further proposed organizational accident causation model ${ }^{[4]}$, and the logical relationship of the accidents causes was shown in Fig. 1. The inherent logic relationship of Reason Model was that accidents had not only a chain reaction of the event itself, but also a penetration of the tissue defect set. The accident precipitating factors and organizations at all levels of defects (or security risk) were long-standing and constantly self-evolution, but they did not necessarily cause unsafe events. When multiple levels of tissue defects simultaneously or in sequence defects on a precipitating factor in the accident, unsafe events would lose multilevel blocking barrier to occur. 


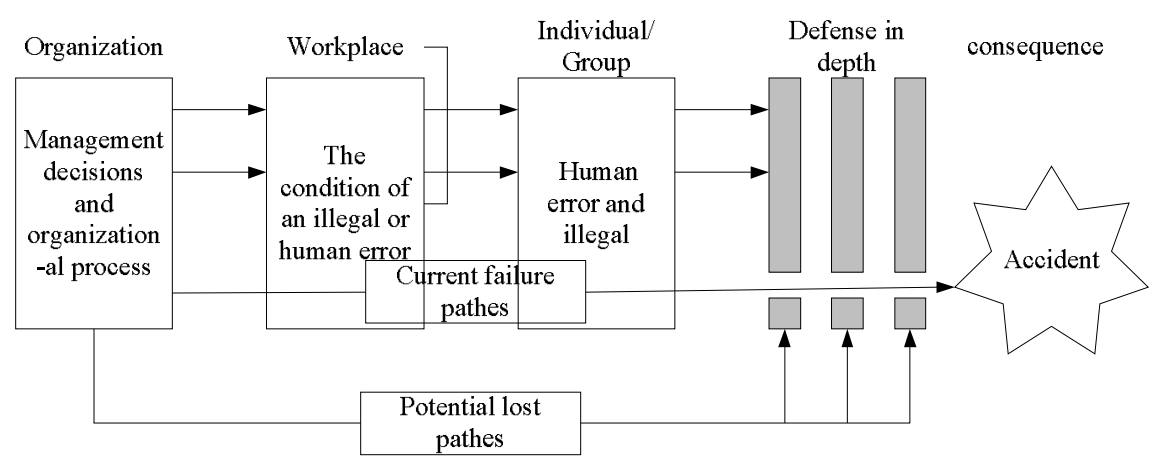

Fig. 1 Organizational accident causation model

The innovation of Reason Model lied in the view of the system ${ }^{[5]}$, including the behavior analysis of people in the unsafe events and the deeper analysis of the potential organizational factors influencing the behavior of people. From the direct effects of integration interaction subsystem and organization level of power to managers and stakeholders and the indirect effects of enterprise culture, they expanded the vision of accident analysis on the full aspects, and the unified logical accident chain reaction would make the theoretical series with all relevant factors.

\section{Genetic model of traffic accidents}

Road traffic accidents are caused by the imbalance of the system that consists of people, vehicle, road and environment. Only by understanding the direct and indirect reasons of the accidents, through eliminating and controlling the causes of the accidents, can we achieve the purpose of preventing and controlling the occurrence of the accidents. In combination with the Reason's organizational accident causation model, a genetic model of traffic accidents is constructed, as shown in Fig. 2.

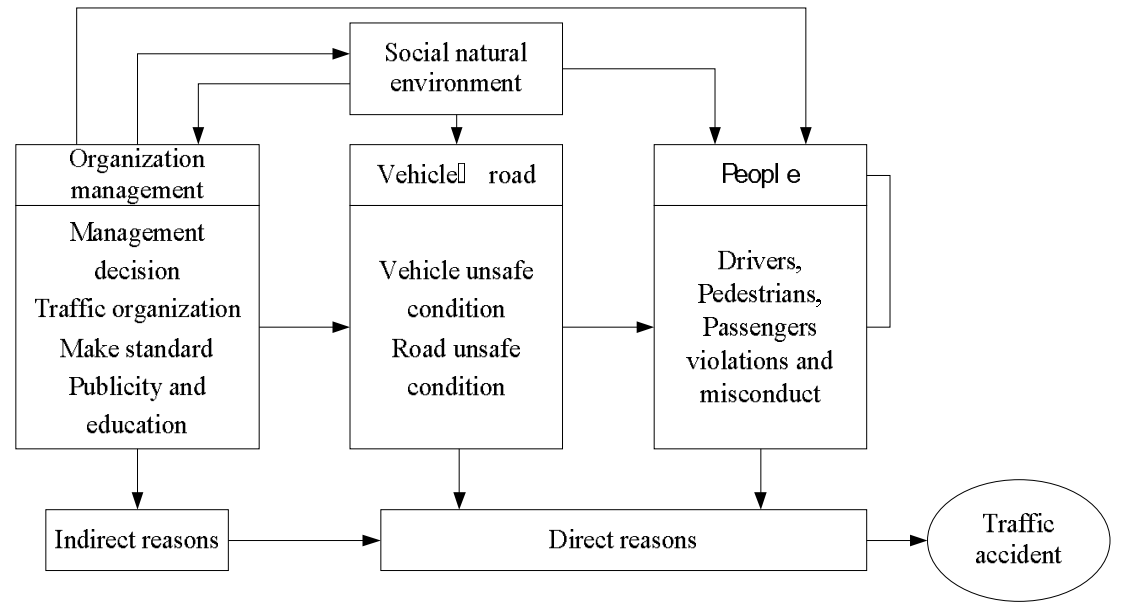

Fig. 2 Genetic model of traffic accidents

In this model, the causes of road traffic accidents are divided into direct and indirect reasons. The direct reasons tell people what happened, and the indirect reasons tell us why they happened. The unsafe behaviors of road traffic participants and the unsafe states of vehicle and road are the direct cause of traffic accidents, but they are the interactional results of road traffic management and social natural environment rather than independent and random phenomena. Therefore, we analyse not only the direct causes, but the indirect reasons. Indirect reasons refer to the defects of organization management department, which are presented by the unsafe behaviors of traffic participants and vehicles and roads. They are the indirect causes of traffic accidents, so usually ignored. Although the organization management department is away from the scene of the accident in time and space, these factors have a significant impact on the occurrence of traffic accidents. The genetic model of traffic accidents emphasizes not only the direct causes of the traffic accidents, but also indirect causes of the transportation system that are the most difficult to detect and cause great harm. Only from two aspects of direct and indirect reasons to take effective measures to eliminate the defects of the system, can we effectively prevent accidents from happening. 


\section{Case study on a large traffic accident}

\section{Case accident survey}

At 16 pm, March 19, 201*, Si** drived a Accord whose driving license was Beijing Y-921** (referred to as the Accord) from west to east to ** highway near the site of the incident. Because in the local ice road the Accord crashed into the right side of the fence and stopped on the driveway with the north front transverse. In order to escape the Accord, a heavy truck (referred to as the truck 1) following it rushed out of the right side of the fence and turned to the right. Then the oncoming Foton heavy tractor-semitrailer whose driving license was Hei D-290**/ heavy stake semi-trailer whose driving license was Hei D-26** (referred to as Foton truck) did not escape in time, so the front right of the Foton truck slightly crushed into the left front of the Accord. After the collision the Foton truck stopped in the carriageways and the Accord stopped on the hard shoulder with two car front flush and toward the east. At 16:30 when Wang** drived a large ordinary Golden Dragon bus whose driving license was Hei L-499** (referred to as the Golden Dragon bus) from the west to the east to the site of the incident, the right front side of it rear-ended the rear left of the Foton truck and stopped at last. 19 people in the Golden Dragon bus were dead and 7 people were injured in accidents, with minor damage to the Accord, the truck 1 and the Foton truck, and Golden Dragon bus seriously damaged.

\section{Case cause of accident}

The materials related with accidents analysis are <Files on Road Traffic Accidents by ** County Public Security Traffic Police Brigade >, <Technical Analysis Reports by State Administration of Work Safety and Joint Expert Group of the Safety Production Supervision and Administration Bureau of the ** Provincial>, <Design Documents and Related Materials of Highway Survey and Design Institute of the ** Provincial>, and <Opinions of the ** Judicial Authentication>.According to these relevant materials, we analyse the traffic accidents combing with the genetic model of traffic accidents, and sum up the causes of the accidents cases.

\section{Personnel factors}

(1) A series of mistakes of the driver of the Golden Dragon bus directly led to the occurrence of the accident. The driver of the Golden Dragon bus replaced the bus to the designated driver without checking his driving license and driving technique. The quasi driving type of the latter's driving license didn't match the bus which he drove. And the bus was exceeding the speed limit when the accident occurred. Besides, the designated driver didn't see the reflective warning sign (triangle warning sign) set by the driver of the accident vehicle on the road ahead. After discovering the dangerous condition, the driver made the improper operation (the vehicle wasn't driven into the passing lane in time) and didn't comprehend the technical performance of the bus equipment. (He unilaterally knew the performance and the effect of the retarder. He thought retarder could slow down the vehicle on snowy and icy road, and it could not only let the vehicle running without deviation and skidding, but also prolong the service life of the brake.) He mistakenly opened the retarder. Moreover, the bus was overbooked by 5 persons.

(2) The driver of Foton truck operated improperly when the accident happened (He braked and steered too quickly on the road with low adhesion). And the truck was overbooked (by the rate of 96\%).

(3) The driver of truck 1 operated improperly when it was dangerous (He improperly braked on the road with low adhesion), and the truck didn't avoid the accident effectively.

(4) The driver of the Accord didn't drove cautiously and his operation was improperly. After the vehicle hit the fence, it stopped on the lane.

\section{Factors of road and vehicle}

Factors of vehicle. Due to collision damage the safety technology structure of the vehicle couldn't be identified, the rest of the vehicle structures and performances could meet the requirements of the relevant technical conditions. But drivers didn't understand the current retarder on the rear axle couldn't be used on the icy road. Otherwise the rear axle will sideslip even flick. 
Factors of road. The longitudinal section where the incident happened was slightly arched. From the west to the east, the road is first uphill and then downhill. The accident happened on the downhill whose slope is $-1.3 \%$. There was ice on the surface of the road, so the adhesion was small whose range was from 0.05 to 0.15 . The braking force coefficient (brake strength) of the current retarder on the rear axle on both side of the tire had exceeded the adhesion coefficient. It would sideslip as long as there was a slight lateral disturbance.

\section{Factors of organizational management}

Passenger transport organization and management department didn't do well in the bus driver's safety organization, publicity and education work. Road traffic law enforcement agencies did not do a good job of work safety duty (They didn't set up warning sings in time). The highways department didn't deal with the road processing well (They didn't let personnel take non slip measures after the traffic police's notice that the road had begun to freeze).

\section{Factors of social natural environment}

(1)Natural environment. The incident road is located in hilly areas. The incident occurred in the downhill where there is no the sun radiation. So ice melt when sunshine came here and then the road became wet. The sun had gone when the accident happened. And the water re-condensed into ice with the temperature below zero, which made the road very slippery. It meant that other section of the road was dry, and there was ice on local special part of the incident section, which could be aware of only in a very short distance.

(2) Social environment. Patrol road traffic police had found that the local section of the road had begun to freeze. And they had informed traffic department. But the traffic department didn't take warning and preventive measures timely. It meant the weak social supervision of the organization and management department, the lack of enforcement of traffic safety laws and regulations and traffic participants' weak safety knowledge and awareness etc.

\section{Genetic model of accidents cases}

Based on the analysis of the four aspects of the accident cases: people, vehicles, roads, and organization and social natural environment, combined with the genetic model of traffic accidents, we get the analysis diagram of the causes of the accidents, which is shown in Fig. 3.

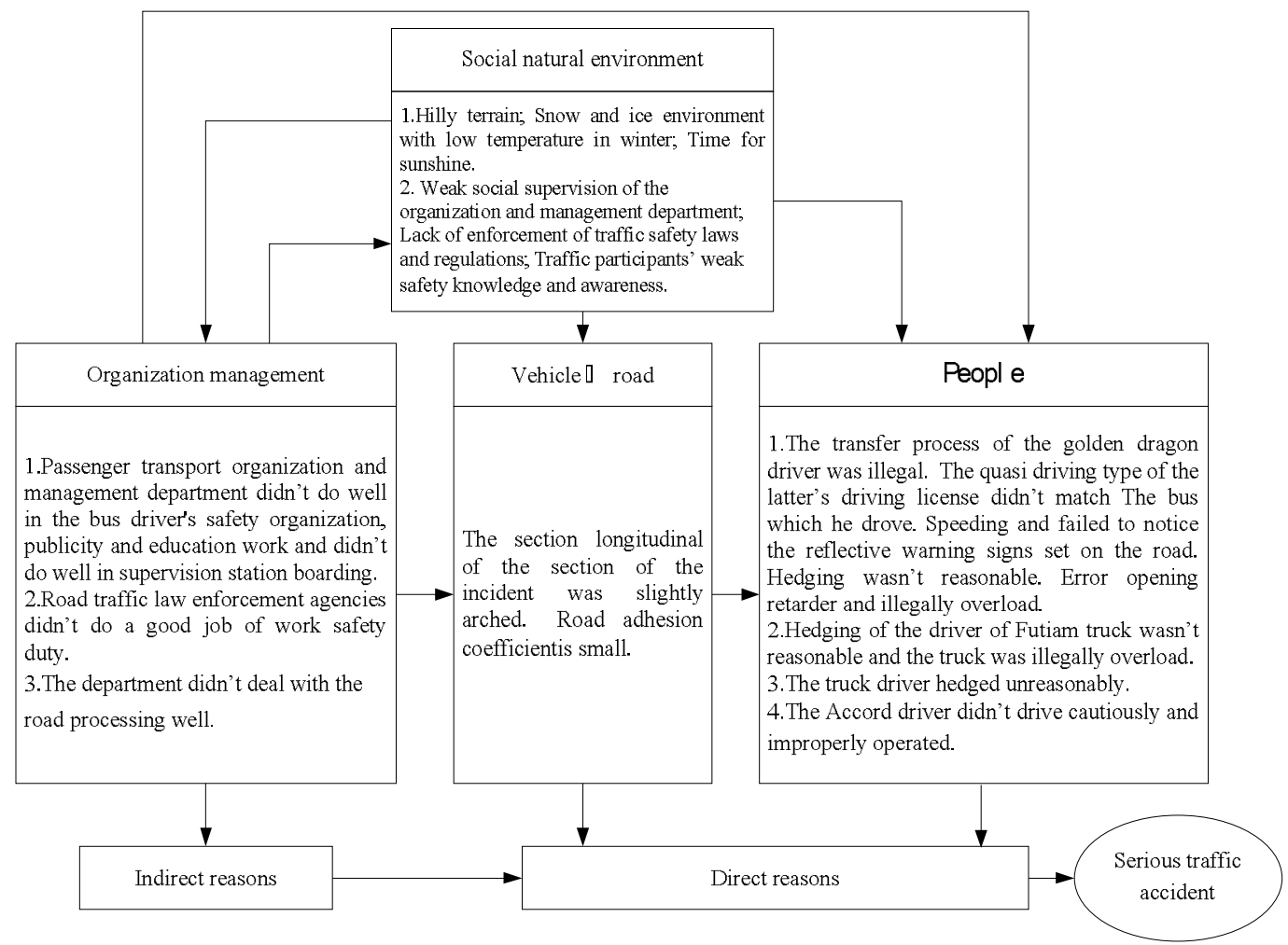

Fig. 3 Analysis diagram of the causes of serious traffic accidents 


\section{Prevention measures for serious road traffic accidents}

The above analysis shows that the occurrence of serious road traffic accidents is not only related to the behavior of traffic participants, vehicle characteristics and structures, road conditions and traffic infrastructures, but also has close relationship with the deeper organization management factors and social natural environment factors. Among them, the main reason is a series of unsafe behavior of drivers. Therefore, we need to analysis people, vehicles and road, organization management and social natural environment at the same time, and comprehensively summarize the causes of road traffic accidents, and put forward the prevention measures for serious traffic accident.

\section{Education promotion measures}

Transport enterprises should improve the responsibility for production safety at all levels and the safety management system, and strengthen safety management, and increase the operation force of the driving people's education and training, and improve drivers' safety awareness and skills and earnestly implement the main responsibility of enterprise safety production. Government departments should increase the propaganda force of traffic safety education. Warn the drivers not to load illegally and improve drivers' active safety awareness.

\section{Engineering and technical measures}

According to the characteristics of relevant road in the area under administration, unite public security, transportation and safety supervision departments to strengthen the investigation and management of hidden danger on bending slope, temporary cliff, waterfront and dangerous road, accident prone sections and road sections whose prevailing conditions are influenced by severe weather. And improve road traffic safety protection facilities. Enterprises should educate and urge drivers and owners to do a good job of vehicle maintenance work conscientiously, in order to make the vehicle in a good state of safety technology. Persons in charge of safety in the traffic safety and subjective department of transportation and transportation enterprises should make full use of GPS monitoring platform, and strengthen the dynamic monitoring of vehicles and the road monitoring of passenger vehicles to prevent the driver's illegal behavior.

\section{Law enforcement and supervision measures}

The traffic police department should strengthen the management and control of road traffic safety, especially the force of patrol in adverse weather conditions. Increase the remind strength about speeding, overcrowding, overloading, illegal loading and other key violations through the whistle, propaganda and other ways. Joint transportation, safety supervision departments to strengthen the measures of government regulation on transport enterprises and build a public service platform for dynamic information of operating vehicles.

\section{Conclusions}

Road traffic accidents are the essential social phenomenon and related to all fields of the society. As long as people have full understanding of them and further study the causes and identify the root of problems and put forward the corresponding preventive measures, the occurrence of the road traffic accidents can be controlled in a reasonable range, especially serious road traffic accidents.

Based on the causes analysis of the typical cases, the article analyses the genetic characteristics of this kind of accidents, and makes a comprehensive analysis for the accident examples with the model diagram of the traffic accident causations. From the perspective of the direct causes of the accidents, it digs out the indirect causes of road traffic accidents, and puts forward measures to prevent and reduce the occurrence of serious traffic accidents from the publicity and education, engineering, law enforcement and regulatory.

\section{Acknowledgements}

This work was financially supported by the Opening Project of Key Laboratory of operation safety technology on transport vehicles, Ministry of Transport, PRC. 


\section{References}

[1] Ren Yuli. First Exploration on the Road Traffic Safety Status and the Analysis Methods of the Traffic Accidents[J]. Road Traffic and Safety,2010,10(2):3-6.

[2] Traffic Management Bureau of the Ministry of public security of the people's Republic of China. Annual Report on Road Traffic Accident Statistics[R].2013:2-3

[3] Reason J. Human Error [M].UK,Cambridge:Cambridge University Press, 1990.

[4] Reason J. A system approach to organization error [J].Ergonomics, 1995,38(8):17-21.

[5] Lv Xuemei, Wang Yonggang, Jing Zengqiang. The Analysis of Civil Aviation Accidents Based on the Reason Model[C].Xi'an: 2006 Annual Conference of the Occupational Safety and Health Association in China,2006:357-360. 